\title{
Multi-Drug Resistant Organism
}

National Cancer Institute

\section{Source}

National Cancer Institute. Multi-Drug Resistant Organism. NCI Thesaurus. Code

C111564.

A microorganism, often a bacterium, that is not susceptible to standard antimicrobial therapies. 